\section{Ji Won Moon, James Ki Shinn, Dalsung Ryu, Se-Yang Oh, Yu Shik Shim, Seung Hwan Yoon}

Department of Neurosurgery, Inha University College of Medicine, Incheon, Korea

\section{Corresponding Author:}

Seung Hwan Yoon

Department of Neurosurgery, Inha University College of Medicine, 366 Seohae-daero, Jung-gu, Incheon 22332, Korea

Tel: +82-32-890-2619

Fax: +82-32-890-3967

E-mail: nsyoon@gmail.com

Received: August 22, 2017

Revised: September 8, 2017

Accepted: September 11, 2017

\title{
Pelvic Incidence Can Be Changed not only by Age and Sex, but also by Posture Used during Imaging
}

Objective: Computed tomography (CT), rather than conventional 2-dimensional radiography, was used to scan and measure pelvic parameters. The results were compared with measurements using X-ray.

Methods: Pelvic parameters were measured using both CT and X-ray in 254 patients who underwent both abdomino-pelvic CT and X-ray at the pelvic site. We assessed the similarity of the pelvic parameters between the 2 exams, as well as the correlations of pelvic parameters with sex and age.

Results: The mean values of the subjects' pelvic parameters measured on X-ray were: sacral slope (SS), $31.6^{\circ}$; pelvic tilt (PT), $18.6^{\circ}$; and pelvic incidence (PI), 50.2 ${ }^{\circ}$ The mean values measured on CT were: SS, $35.1^{\circ}$; PT, $11.9^{\circ}$; and $\mathrm{PI}, 47.0^{\circ}$. PT was found to be $4.07^{\circ}$ higher on $\mathrm{X}$-ray and $2.98^{\circ}$ higher on $\mathrm{CT}$ in women, with these differences being statistically significant $(p<0.001, p<0.001)$. PI was $4.10^{\circ}$ higher on X-ray and $2.78^{\circ}$ higher on CT in women, with these differences also being statistically significant $(p<0.001, p=0.009)$. We also observed a correlation between age and PI. For men, this correlation coefficient was 0.199 measured using $\mathrm{X}$-ray and 0.184 measured using CT. For women, this correlation coefficient was 0.423 measured using X-ray and 0.372 measured using CT.

Conclusion: When measured using CT compared to X-ray, SS increased by $3.5^{\circ}, \mathrm{PT}$ decreased by $6.7^{\circ}$, and $\mathrm{PI}$ decreased by $3.2^{\circ}$. There were also statistically significant differences in $\mathrm{PT}$ and PI between male and female subjects, while PI was found to increase with age.

Key Words: Pelvic incidence, Posture, Age factors, Sex factors, Sagittal imbalance

\section{INTRODUCTION}

Sagittal spinal morphology is different in each individual. Such differences in anatomical structure have been studied by During et al. ${ }^{9)}$, who studied lower back system, lumbar lordosis, and pelvic parameters. Later, the concept of pelvic incidence (PI) was established by DuvalBeaupère et al. ${ }^{11)}$ and Legaye et al. $^{24)}$, after which numerous studies have been conducted.

PI, the sum of pelvic tilt (PT), and sacral slope (SS), are some of the pelvic parameters most commonly used. Among these, PI is known to not change during lifetime after bone growth. Although it has no association with sex or age, it has been reported to be associated with anatomical changes caused by spinal disease ${ }^{11,24,28,29)}$. There have been a number of studies on the association between spinal disease and pelvic parameters. These studies have shown that correcting sagittal balance in consideration of pelvic parameters leads to good prognosis during surgical treatment of spinal deformity ${ }^{7,10,25,31-34)}$. However, after Mendoza-Lattes et al. ${ }^{30)}$ dem- onstrated an association between age and PI in 2010, additional studies have reported an association between PI and age. Meanwhile, other studies have documented an association between PI and sex, which were previously thought to be unassociated ${ }^{4,37,38)}$. Although it is generally perceived that the association between age and PI is a result of PI changes caused by sagittal imbalance or an increase in sacral-femoral distance following aging, inaccurate measurements using 2-dimensional (2D) radiographic images may also contribute to such observed changes. This imaging method has been the measurement standard of pelvic parameters since 1985, which was when the concept of pelvic parameters was first introduced ${ }^{15,22,38)}$. In cases imaged using 2D radiography, it is difficult to verify 2 femoral heads due to the projective nature of X-ray images ${ }^{36}$. Recently, studies that involve PI measurement using computed tomography (CT) have been reported, but they are still insufficiently characterized in relation to previous measuring modalities ${ }^{36,37)}$. In this study, we measured pelvic parameters using CT, which is widely performed in the spine-pelvic area, 
and directly compared them with pelvic parameters measured by X-ray to determine their correlation.

\section{MATERIALS AND METHODS}

\section{Subjects}

Subjects who provided written informed consent were enrolled from Inha University Hospital and underwent both abdominopelvic CT and X-ray of the pelvic region from January 2011 to December 2015. We then compared the CT and X-ray measurements from the same subjects. The subjects were not excluded due to the presence of any disease at this point in the study. A total of 474 subjects were examined. There were many cases in which subjects underwent multiple examinations since we included all examinations conducted over the preceding 5 years. In such cases, we included subjects who experienced a short gap between the time of CT and X-ray examinations. In contrast, to minimize the reduction of data values caused by a large gap between the time of CT and X-ray examinations, 97 subjects whose gap bet- ween studies was longer than 1 year between the time of CT and X-ray examinations were excluded. In addition, 123 subjects who had undergone spine surgery in the lumbar-sacral region, pelvis surgery, or femur surgery were additionally excluded. Hence, a total of 254 subjects (126 male and 128 female subjects) were included in this study.

\section{Measurement of Pelvic Parameters}

All radiological examinations were conducted in subjects according to a general examination procedure. All X-ray imaging was conducted in a standing position and all CT imaging was conducted in a supine position.

Pelvic parameters were measured using Maroview picture archiving communications system (PACS). Using the PI angle measurement tool included in PACS, we sought to obtain more accurate measurements. Then, pelvic parameter was determined by 2 different observers in an effort to reduce estimation error. The measured value of two observers' intraclass correlation coefficient was statistically significant as it was 0.919 and the average value of the 2 measured value was used as the data for this study. In the X-ray, both femur heads were determined and pelvic parameters were measured using the PI angle measurement tool. In this study, the following method including PI value based on CT scan was used due to the fact that there was no software to perform 3-dimensional image reformation which Vrtovec et al. $^{39)}$ have used. The left femur head was first determined using the sagittal image and the center of the femur was found. The right femur head was then identified, while the center of the femur was identified in the same way. Then, the position of the center of each femur was marked on the midline image of the spine to obtain the accurate center point of the femur head, and pelvic parameters were measured at this state using the PI angle measurement tool (Fig. 1).

\section{Statistical Analysis}

The association between the examination method and the sex of subjects was analyzed and reported according to the mean and standard deviation. IBM SPSS ver. 18.0 (IBM Co., Armonk, NY, USA) was used for statistical analysis. The correlation between pelvic parameters from each examination method was analyzed using a paired t-test, and the correlation between pelvic parameters from male and female subjects was analyzed using an independent samples t-test. The correlation between age and PI was analyzed using a linear regression analysis and checked Pearson correlation coefficient, while $\mathrm{p}<0.05$ was assumed to indicate statistical significance in all measurements.

\section{RESULTS}

\section{Subjects}

The mean age of the 254 subjects was $61.3 \pm 14.7$ years (range, 18-92 years). The mean age of the 126 male subjects was $62.3 \pm$ 13.9 years (20-92 years), and the mean age of the 128 female subjects was $60.7 \pm 15.6$ years (18-88 years). The difference in age according to sex was not statistically significant $(\mathrm{p}=0.293)$.

\section{Results of Pelvic Parameters}

The mean pelvic parameters of all subjects measured on X-ray

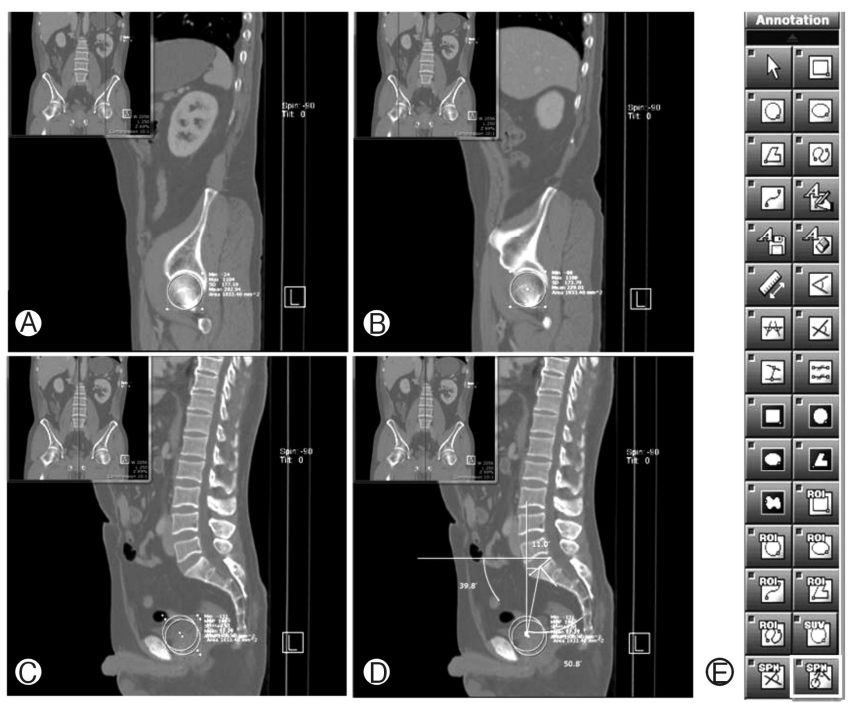

Fig. 1. Measurements were obtained from the computed tomograhic image using the pelvic incidence angle tool of picture archiving communications system (PACS). (A) The left femur center was identified. (B) The right femur center was identified. (C) Both femur centers were marked on the midline. (D) Pelvic parameters were measured using the pelvic incidence angle measurement tool. (E) The pelvic incidence angle measurement tool button provided by PACS. 
were SS $31.6^{\circ} \pm 7.4^{\circ}$, PT $18.6^{\circ} \pm 7.7^{\circ}$, and PI $50.2^{\circ} \pm 9.0^{\circ}$, while the mean pelvic parameters measured on CT were SS $35.1^{\circ} \pm 6.7^{\circ}$, PT $11.9^{\circ} \pm 5.7^{\circ}$, and PI $47.0^{\circ} \pm 8.5^{\circ}$. When the measurements from X-ray and CT were compared, the mean PT was $6.7^{\circ}$ smaller, the mean SS was $3.5^{\circ}$ larger, and the mean PI was $3.2^{\circ}$ smaller in CT, and these differences were statistically significant $(\mathrm{p}<$ 0.001) (Table 1). The difference in pelvic parameters according to the examination method was statistically significant regardless of $\operatorname{sex}(\mathrm{p}<0.001)$.

When pelvic parameters were compared between male and female subjects, there was no statistically significant difference in SS when it was examined by X-ray and CT $(\mathrm{p}=0.967, \mathrm{p}=0.814)$ (Table 2). However, PT was $4.07^{\circ}$ larger in female subjects when examined using X-ray and $2.98^{\circ}$ larger when examined using $\mathrm{CT}$, and these differences were statistically significant $(\mathrm{p}<0.001$, $\mathrm{p}<0.001)$. PI was $4.10^{\circ}$ larger in females when examined using $\mathrm{X}$-ray and $2.78^{\circ}$ larger when examined using CT, and these differences were also statistically significant $(p<0.001, p=0.009)$.

Pelvic parameters according to age were measured. The results indicated an association in which PI increased with age (Fig. 2). Such association between age and PI was statistically significant regardless of X-ray or CT, and the association was observed in both male and female subjects, subjects. In males, this correlation coefficient was 0.199 when measured using X-ray $(p=0.025)$ and 0.184 when measured using CT $(p=0.039)$. In female subjects, the correlation coefficient was 0.423 when measured using X-ray $(\mathrm{p}<0.001)$ and 0.372 when measured using CT $(\mathrm{p}<0.001)$.

\section{DISCUSSION}

Sagittal balance is affected by the spine and anatomical structures around the pelvis ${ }^{17}$. When sagittal imbalance occurs locally, it can be resolved by correction through compensation in the spine itself. However, when such compensation reaches its limit, the pelvis, hip joint, and knee joint are involved in compensation $^{6,8)}$. Therefore, several attempts have been made to develop an index that demonstrates the association between the spine and pelvis, with PI being the most commonly used among them. The importance of this index is evidenced by its clinical use for determining the prognosis of spinal lesions ${ }^{2,3,33-35)}$. To improve the accuracy of measuring, Vrtovec et al. ${ }^{39)}$ reported PI measurements analyzed by CT from 370 healthy patients in 2012, while Jentzsch et al. ${ }^{16}$, in a PI study, reported the results obtained from CT scans of 620 subjects in 2013. These studies by Vrtovec et al..$^{39)}$ and Jentzch et al. ${ }^{16)}$ used CT instead of previous data based on plain X-ray. Vrtovec et al. ${ }^{39)}$ indicated that the mean PI of 189 male subjects was $46.6^{\circ} \pm 9.2^{\circ}$, the mean PI of 181 female subjects was $47.6^{\circ} \pm 10.7^{\circ}$, and the mean PI of all 370 subjects (mean age, $41.5 \pm 20.1$ years) was $47.1^{\circ} \pm 10.0^{\circ}$. In a study by Jentzsch et al. ${ }^{16}$, the mean PI of 403 male subjects (mean age, 43.0 years) was $51.1^{\circ}$, the mean PI of 193 female subjects was $50.3^{\circ}$, and the mean PI of all 596 subjects was $50.8^{\circ}$. When compared to measurements from our study (mean PI of $45.6^{\circ} \pm 7.3^{\circ}$ in male subjects, mean PI of $48.4^{\circ} \pm 9.4^{\circ}$ in female sub-
Table 1. Difference of pelvic parameters between X-ray and CT

\begin{tabular}{|c|c|c|c|}
\hline Pelvic parameter & Mean $\pm S D$ & $\begin{array}{c}\text { Difference } \\
\text { (X-ray value - CT value) }\end{array}$ & p-value \\
\hline \multicolumn{4}{|l|}{ All (254 cases) } \\
\hline SS by X-ray $\left(^{\circ}\right)$ & $31.6 \pm 7.4$ & \multirow{2}{*}{-3.5} & \multirow{2}{*}{$<0.0001$} \\
\hline SS by $\mathrm{CT}\left({ }^{\circ}\right)$ & $35.1 \pm 6.7$ & & \\
\hline PT by X-ray $\left(^{\circ}\right)$ & $18.6 \pm 7.7$ & \multirow{2}{*}{6.7} & \multirow{2}{*}{$<0.0001$} \\
\hline PT by CT $\left(^{\circ}\right)$ & $11.9 \pm 5.7$ & & \\
\hline PI by X-ray $\left(^{\circ}\right)$ & $50.2 \pm 9.0$ & \multirow{2}{*}{3.2} & \multirow{2}{*}{$<0.0001$} \\
\hline PI by CT $\left(^{\circ}\right)$ & $47.0 \pm 8.5$ & & \\
\hline \multicolumn{4}{|l|}{ Male (126 cases) } \\
\hline SS by X-ray $\left(^{\circ}\right)$ & $31.6 \pm 7.0$ & \multirow{2}{*}{-3.6} & \multirow{2}{*}{$<0.0001$} \\
\hline SS by CT $\left(^{\circ}\right)$ & $35.2 \pm 6.3$ & & \\
\hline PT by X-ray $\left(^{\circ}\right)$ & $16.6 \pm 6.8$ & \multirow{2}{*}{6.2} & \multirow{2}{*}{$<0.0001$} \\
\hline PT by CT $\left(^{\circ}\right)$ & $10.4 \pm 5.3$ & & \\
\hline PI by X-ray $\left(^{\circ}\right)$ & $48.1 \pm 7.0$ & \multirow{2}{*}{2.6} & \multirow{2}{*}{$<0.0001$} \\
\hline PI by $\mathrm{CT}\left({ }^{\circ}\right)$ & $45.6 \pm 7.3$ & & \\
\hline \multicolumn{4}{|l|}{ Female (128 cases) } \\
\hline SS by X-ray $\left(^{\circ}\right)$ & $31.6 \pm 7.7$ & \multirow{2}{*}{-3.4} & \multirow{2}{*}{$<0.0001$} \\
\hline SS by $\mathrm{CT}\left({ }^{\circ}\right)$ & $35.0 \pm 7.0$ & & \\
\hline PT by X-ray $\left(^{\circ}\right)$ & $20.6 \pm 8.1$ & \multirow{2}{*}{7.3} & \multirow{2}{*}{$<0.0001$} \\
\hline PT by CT $\left(^{\circ}\right)$ & $13.4 \pm 5.7$ & & \\
\hline PI by X-ray $\left(^{\circ}\right)$ & $52.2 \pm 10.3$ & \multirow{2}{*}{3.9} & \multirow{2}{*}{$<0.0001$} \\
\hline PI by $\mathrm{CT}\left({ }^{\circ}\right)$ & $48.4 \pm 9.4$ & & \\
\hline
\end{tabular}

CT, computed tomography; SD, standard deviation; SS, sacral slope; PT, pelvic tilt; PI, pelvic incidence.

Table 2. Difference of pelvic parameters for sex

\begin{tabular}{|c|c|c|c|}
\hline Pelvic parameter & Mean $\pm S D$ & $\begin{array}{c}\text { Difference } \\
\text { (Male value - female value) }\end{array}$ & p-value \\
\hline \multicolumn{4}{|l|}{ SS by X-ray $\left({ }^{\circ}\right)$} \\
\hline Male & $31.6 \pm 7.0$ & \multirow{2}{*}{-0.04} & \multirow{2}{*}{$<0.967$} \\
\hline Female & $31.6 \pm 7.7$ & & \\
\hline \multicolumn{4}{|l|}{ SS by CT $\left(^{\circ}\right)$} \\
\hline Male & $35.2 \pm 6.3$ & \multirow{2}{*}{0.20} & \multirow{2}{*}{$<0.814$} \\
\hline Female & $35.0 \pm 7.0$ & & \\
\hline \multicolumn{4}{|l|}{ PT by X-ray $\left(^{\circ}\right)$} \\
\hline Male & $16.6 \pm 6.8$ & \multirow{2}{*}{-4.07} & \multirow{2}{*}{$<0.0001$} \\
\hline Female & $20.6 \pm 8.1$ & & \\
\hline \multicolumn{4}{|l|}{ PT by $\mathrm{CT}\left({ }^{\circ}\right)$} \\
\hline Male & $10.4 \pm 5.3$ & \multirow{2}{*}{-2.98} & \multirow{2}{*}{$<0.0001$} \\
\hline Female & $13.4 \pm 5.7$ & & \\
\hline \multicolumn{4}{|l|}{ PI by X-ray $\left(^{\circ}\right)$} \\
\hline Male & $48.1 \pm 7.0$ & \multirow{2}{*}{-4.10} & \multirow{2}{*}{$<0.0001$} \\
\hline Female & $52.2 \pm 10.3$ & & \\
\hline \multicolumn{4}{|l|}{ PI by $\mathrm{CT}\left({ }^{\circ}\right)$} \\
\hline Male & $45.6 \pm 7.3$ & \multirow{2}{*}{-2.78} & \multirow{2}{*}{$<0.009$} \\
\hline Female & $48.4 \pm 9.4$ & & \\
\hline
\end{tabular}

SD, standard deviation; SS, sacral slope; CT, computed tomography; PT, pelvic tilt; PI, pelvic incidence. 
jects, and mean PI of $47.0^{\circ} \pm 8.5^{\circ}$ in all subjects) our study results were found to be similar to those of the study by Vrtovec et al. ${ }^{39)}$ Furthermore, the overall mean PI was $3.8^{\circ}$ lower than the results reported by Jentzsch et al. ${ }^{16}$. However, this observation that the mean PI values were similar or only slightly lower than those of the previous studies, despite the mean age of subjects in this study being approximately 20 years older, contradicts our finding that age is associated with PI. The fact that our mean PI values were smaller than the measurements from study of Jentzsch et al. ${ }^{16)}$, even though the subjects of our study are older, is particularly interesting, and it raises a question whether this is due to different results affected by race, which is another factor in addition to age and gender. Notably, we believe that the difference in the anatomical structure or living habits of Asians and Caucasians resulted in the differences in mean PI. Although there have been no studies designed to analyze the association between race and PI, the observation that mean PIs measured from Asians are generally lower than mean PIs measured from Caucasians requires further investigation (Table $3)^{1,5,7,13,14,18-21,23,31,36,37)}$. Moreover, a direct comparison could not

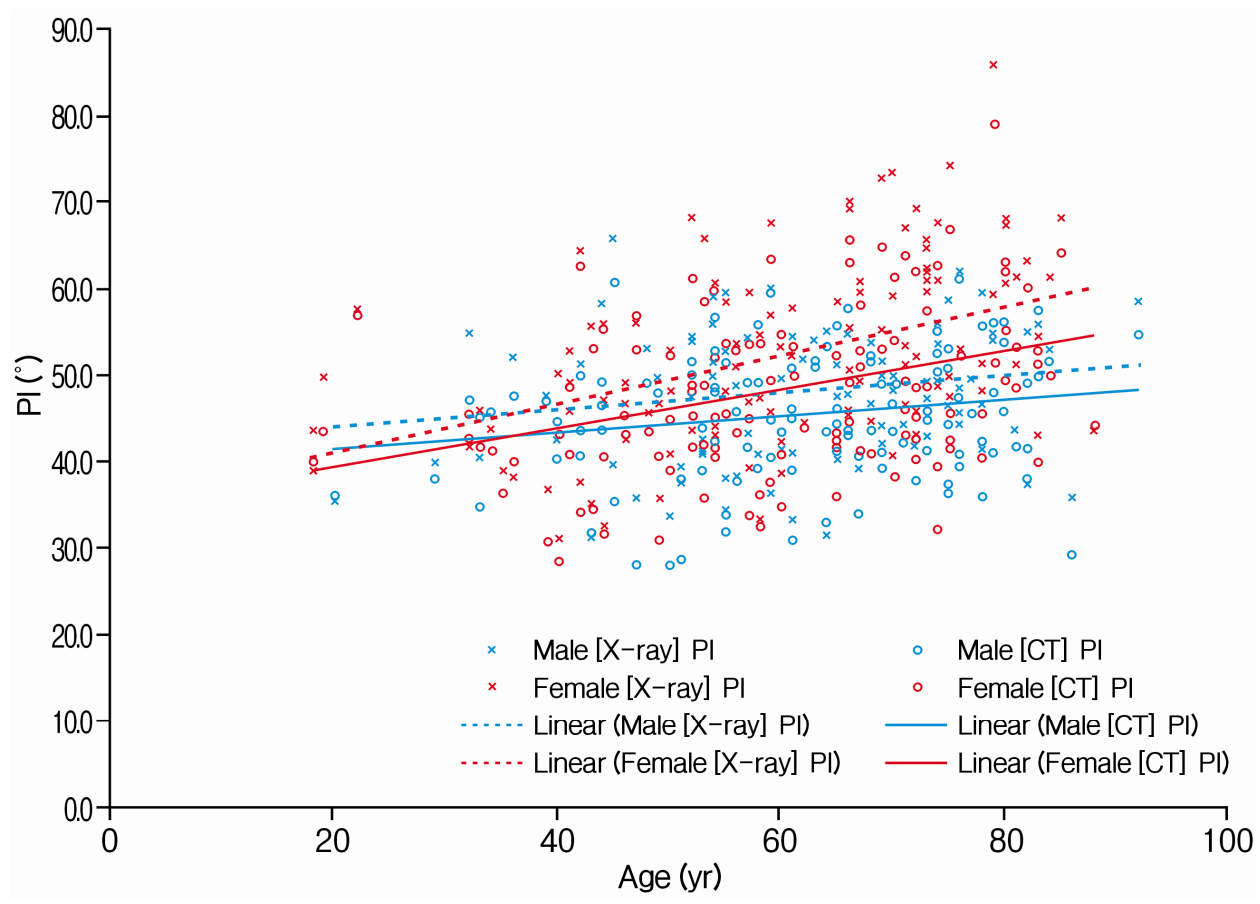

Fig. 2. Correlation between age and pelvic incidence (PI) was analyzed using linear regression analysis. CT, computed tomography.

Table 3. Difference of pelvic incidence (PI) for race

\begin{tabular}{|c|c|c|c|c|c|c|}
\hline Race & Country & Year & No.* & 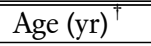 & $2 \mathrm{PI}\left({ }^{\circ}\right)^{\top}$ & Reference \\
\hline \multirow[t]{6}{*}{ Caucasians } & France & 2002 & 100 & $26.5 \pm 4.0$ & $51.7 \pm 11.5$ & Vaz et al. ${ }^{36)}$ \\
\hline & Canada & 2004 & 160 & $25.7 \pm 4.4$ & $51.8 \pm 5.3$ & Labelle et al. ${ }^{20)}$ \\
\hline & France & 2005 & 160 & 27.0 & $51.9 \pm 10.7$ & Roussouly et al. $^{31)}$ \\
\hline & France & 2006 & 149 & $30.8 \pm 6.0$ & $53.1 \pm 9.0$ & Boulay et al. ${ }^{7}$ \\
\hline & Belgium & 2007 & 145 & $40.7 \pm 18.7$ & $50.2 \pm 10.6$ & Legaye $^{23)}$ \\
\hline & France & 2007 & 154 & $27.0 \pm 8.0$ & $52.0 \pm 10.7$ & Barrey et al. ${ }^{5)}$ \\
\hline \multirow[t]{5}{*}{ Asians } & Korea & 2010 & 166 & $21.8 \pm 1.3$ & $46.4 \pm 7.7$ & Ahn et al. ${ }^{1)}$ \\
\hline & Korea & 2011 & 132 & $64.1 \pm 6.3$ & $48.4 \pm 8.6$ & Kang et al. ${ }^{19)}$ \\
\hline & Japan & 2011 & 425 & $43.8 \pm 13.9$ & $46.7 \pm 8.7$ & Kanemura et al. ${ }^{18)}$ \\
\hline & Korea & 2012 & 117 & 27.5 & $47.8 \pm 8.7$ & Lee et al. ${ }^{21)}$ \\
\hline & Japan & 2014 & 86 & $35.9 \pm 11.1$ & $46.7 \pm 8.9$ & Endo et al. ${ }^{13)}$ \\
\hline
\end{tabular}

*Number of subjects. ${ }^{\dagger}$ Mean \pm standard deviation. 
Table 4. Review of studies on pelvic parameters

\begin{tabular}{|c|c|c|c|c|c|c|c|}
\hline Reference & Year & No. ${ }^{*}$ & Age $(y r)^{\dagger}$ & PI $\left(^{\circ}\right)^{\dagger}$ & $2 \mathrm{SS}\left({ }^{\circ}\right)^{\dagger}$ & $\bar{P}^{\mathrm{PT}\left({ }^{\circ}\right)^{\dagger}}$ & Description \\
\hline Vaz et al. $^{36)}$ & 2002 & 100 & $26.5 \pm 4.0$ & $51.7 \pm 11.5$ & $39.4 \pm 9.3$ & $12.3 \pm 5.9$ & - \\
\hline Labelle et al. ${ }^{20)}$ & 2004 & 160 & $25.7 \pm 4.4$ & $51.8 \pm 5.3$ & $39.7 \pm 4.1$ & $12.1 \pm 3.2$ & - \\
\hline Roussouly et al. ${ }^{31)}$ & 2005 & 160 & 27.0 & $51.9 \pm 10.7$ & $40.0 \pm 8.2$ & $12.0 \pm 6.5$ & - \\
\hline Boulay et al. ${ }^{7}$ & 2006 & 149 & $30.8 \pm 6.0$ & $53.1 \pm 9.0$ & $42.0 \pm 7.0$ & $12.0 \pm 6.4$ & - \\
\hline Legaye $^{23)}$ & 2007 & 145 & $40.7 \pm 18.7$ & $50.2 \pm 10.6$ & $38.8 \pm 6.6$ & $11.5 \pm 5.9$ & - \\
\hline Barrey et al. $^{5 \text { ) }}$ & 2007 & 154 & $27.0 \pm 8.0$ & $52.0 \pm 10.7$ & $40.0 \pm 8.2$ & $12.0 \pm 6.5$ & - \\
\hline Vialle et al. $^{37)}$ & 2005 & 190 & - & $53.0 \pm 10.6$ & $41.0 \pm 8.5$ & $13.0 \pm 6.0$ & Males \\
\hline Vialle et al. $^{37)}$ & 2005 & 110 & - & $56.0 \pm 10.0$ & $43.2 \pm 8.4$ & $13.6 \pm 6.0$ & Females \\
\hline Mac-Thiong et al. $^{27)}$ & 2010 & 354 & $37.9 \pm 14.7$ & $52.7 \pm 10.0$ & $39.8 \pm 7.9$ & $12.7 \pm 7.0$ & Males \\
\hline Mac-Thiong et al. $^{27)}$ & 2010 & 355 & $37.7 \pm 13.9$ & $52.4 \pm 10.8$ & $39.3 \pm 8.0$ & $13.4 \pm 6.7$ & Females \\
\hline
\end{tabular}

PI, pelvic incidence; SS, sacral slope; PT, pelvic tilt.

*Number of subjects. ${ }^{\dagger}$ Mean \pm standard deviation.

be made with our study results due to the lack of reports on PT or SS measured from CT.

Numerous studies have reported the mean PIs measured by X-ray over the preceding 30 years. Among them, 8 studies measured pelvic parameters in more than 100 normal subjects in addition to abnormally balanced people (Table 4$)^{5,7,20,23,27,31,36,37}$. The lowest mean PI in these subjects was $50.2^{\circ} \pm 10.6^{\circ}$, which was reported by Legaye et al..$^{23)}$, and the highest mean PI was $54.7^{\circ} \pm$ $10.6^{\circ}$, which was reported by Vialle et al. ${ }^{37}$. Although the measurements from these previous studies were not too different from $50.2^{\circ} \pm 9.0^{\circ}$, as measured in our study, the authors in these studies presented the lowest mean PI values across various studies that were conducted using a method similar to CT in Western countries $^{23,37}$. These results are likely to be affected by race, as described above. Furthermore, the mean SS and PT measured from X-ray were $31.6^{\circ} \pm 7.4^{\circ}$ and $18.6^{\circ} \pm 7.7^{\circ}$, respectively, which were different from previously reported mean SS and PT in healthy subjects (i.e., the mean SS was $38.8^{\circ}-42.0^{\circ}$ and the mean PT was $11.5^{\circ}-13.2^{\circ}$ ). The SS value was $8^{\circ}$ smaller and the mean PT was $6^{\circ}$ larger. This difference in pelvic parameter was likely due to race.

Initially, pelvic parameters were thought to be unchanged between standing and the supine position; however, our results indicate that PI is increased by $3.2^{\circ}$, SS is decreased by $3.5^{\circ}$, and PT is increased by $6.7^{\circ}$ upon standing compared to the supine position using X-ray imaging in the standing position and CT in the supine position. This is similar to the results obtained by Eddine et al. ${ }^{12)}$, who reported that the PI increased by $3.2^{\circ}$, SS decreased by $4.0^{\circ}$, and PT increased by $6.2^{\circ}$ when standing and supine positions were compared. The fact that similar results were obtained in the study by Eddine et al. ${ }^{12)}$ when X-ray examination was also used in the supine position suggests that X-ray or CT examination itself does not affect the measurements and only the differences from posture were reflected in the results. The variability of measuring PI from X-ray was already reported to be between $3^{\circ}-6^{\circ 11}$. Since we found that the difference between X-ray and CT PI values is $3.2^{\circ}$, we are unable to draw definitive conclusions. Therefore, more definitive findings can be obtained if the PI value according to the posture change is measured only by CT. However, in this study, we wanted to determine whether there was a difference between pelvic parameters measured by $\mathrm{X}$-ray and pelvic parameters measured by CT on the same subjects. Therefore, there are limitations in the study. In conclusion, pelvic parameters on X-ray and CT were statistically significant for the same subjects.

Our study revealed that mean PT and PI values can be statistically significantly different according to sex. When examined through X-ray, the mean PT was larger by $4.07^{\circ}$ and the mean PI was larger by $4.10^{\circ}$ in female subjects. Additionally, when examined through CT, the mean PT was larger by $2.98^{\circ}$ and the mean PI was larger by $2.78^{\circ}$ in female subjects. There was no statistically significant difference in mean SS between male and female subjects. In fact, the association between sex and PI is controversial; however, studies reporting the association between sex and PI have argued that the correlation between female subjects and PI is stronger than the correlation between male subjects and PI. Furthermore, our study also showed that the correlation between female subjects and PI was stronger ${ }^{26,37}$. If our finding of an association between sex and PI is accurate, our study additionally revealed that the factor affecting PI is PT. The difference in PT and PI by sex can be explained by the difference in pelvic structure in male and female subjects, which should be further investigated in future studies.

Another finding revealed by this study is that the increase in age is associated with the increase in PI. According to report of Vrtovec et al. ${ }^{38)}$, aging extends PI by increasing the sacral-femoral distance and consequently causing changes in pelvic morphology. For this reason, an increase in PT leads to an increase in PI. Meanwhile, a study by Jentzsch et al. ${ }^{16}$ reported no association between age and PI. The results of this study have verified the correlation between aging and increase in PI, just as it was verified in the study by Vrtovec. Furthermore, the authors also observed the same result that an increase in PT affects an increase in PI. In addition, it was found that a correlation between age and PI was statistically significant regardless of sex. Such associa- 
tion between age and PI was statistically significant regardless of X-ray or CT.

This study is limited by the duration of time between that passed between the CT and X-ray examinations. CT and X-ray were performed simultaneously in only 31 subjects. In order to increase the number of subjects, we included subjects whose gap between studies was shorter than 1 year between the time of CT and X-ray examinations. Moreover, as this is a retrospective study of medical records of patients who visited our hospital, Berkson's bias might also have interfered with the result.

\section{CONCLUSION}

In this study, pelvic parameters were measured from the same subjects using X-ray and CT. Then, the correlation between pelvic parameters according to examination method was directly compared. In addition, pelvic parameters according to changes in posture were also analyzed. SS was larger by $3.5^{\circ}$, PT was smaller by $6.7^{\circ}$, and PI was smaller by $3.2^{\circ}$ when the parameters were measured using CT rather than X-ray. This change in pelvic parameters is likely due to the change from standing position to supine position used for this study. Furthermore, female subjects exhibit a higher PI than do males, which was statistically significant.

Furthermore, our results indicated an association between age and PI through linear regression analysis. This association was observed using both X-ray and CT examinations as well as in both male and female subjects; however, the correlation was stronger in female subjects.

\section{CONFLICT OF INTEREST}

No potential conflict of interest relevant to this article was reported.

\section{REFERENCES}

1. Ahn YJ, Kim YB, Kang KB, Lee SW, Kim Y: Variations in sagittal spinopelvic parameters according to the lumbar spinal morphology in healthy Korean young men. J Korean Soc Spine Surg 17:66-73, 2010

2. Araújo F, Lucas R, Alegrete N, Azevedo A, Barros H: Sagittal standing posture, back pain, and quality of life among adults from the general population: a sex-specific association. Spine (Phila Pa 1976) 39:E782-794, 2014

3. Bae JS, Jang JS, Lee SH, Kim JU: Radiological analysis of lumbar degenerative kyphosis in relation to pelvic incidence. Spine J 12: 1045-1051, 2012

4. Bao H, Liabaud B, Varghese J, Lafage R, Diebo BG, Jalai CM, et al: Does pelvic incidence increase with age? An analysis of 1625 adults. Spine J 16:S356-S357, 2016

5. Barrey C, Jund J, Noseda O, Roussouly P: Sagittal balance of the pelvis-spine complex and lumbar degenerative diseases. A compa0 rative study about 85 cases. Eur Spine J 16:1459-1467, 2007

6. Barrey C, Roussouly P, Le Huec JC, D’Acunzi G, Perrin G: Com- pensatory mechanisms contributing to keep the sagittal balance of the spine. Eur Spine J 22 Suppl 6:S834-841, 2013

7. Boulay C, Tardieu C, Hecquet J, Benaim C, Mouilleseaux B, Marty $\mathrm{C}$, et al: Sagittal alignment of spine and pelvis regulated by pelvic incidence: standard values and prediction of lordosis. Eur Spine J 15:415-422, 2006

8. Cho KJ, Suk SI, Park SR, Kim JH, Kang SB, Kim HS, et al: Risk factors of sagittal decompensation after long posterior instrumentation and fusion for degenerative lumbar scoliosis. Spine (Phila Pa 1976) 35:1595-1601, 2010

9. During J, Goudfrooij H, Keessen W, Beeker TW, Crowe A: Toward standards for posture. Postural characteristics of the lower back system in normal and pathologic conditions. Spine (Phila Pa 1976) 10:83-87, 1985

10. Duval-Beaupere G, Marty C, Barthel F, Boiseaubert B, Boulay Ch, Commard MC, et al: Sagittal profile of the spine prominent part of the pelvis. Stud Health Technol Inform 88:47-64, 2002

11. Duval-Beaupère G, Schmidt C, Cosson P: A Barycentremetric study of the sagittal shape of spine and pelvis: the conditions required for an economic standing position. Ann Biomed Eng 20:451-462, 1992

12. Eddine TA, Migaud H, Chantelot C, Cotten A, Fontaine C, Duquennoy A: Variations of pelvic anteversion in the lying and standing positions: analysis of 24 control subjects and implications for CT measurement of position of a prosthetic cup. Surg Radiol Anat 23:105-110, 2001

13. Endo K, Suzuki H, Nishimura H, Tanaka H, Shishido T, Yamamoto $\mathrm{K}$ : Characteristics of sagittal spino-pelvic alignment in Japanese young adults. Asian Spine J 8:599-604, 2014

14. Hu P, Yu M, Sun Z, Li W, Jiang L, Wei F, et al: Analysis of global sagittal postural patterns in asymptomatic Chinese Adults. Asian Spine J 10:282-288, 2016

15. Jackson RP, Kanemura T, Kawakami N, Hales C: Lumbopelvic lordosis and pelvic balance on repeated standing lateral radiographs of adult volunteers and untreated patients with constant low back pain. Spine (Phila Pa 1976) 25:575-586, 2000

16. Jentzsch T, Geiger J, Bouaicha S, Slankamenac K, Nguyen-Kim TD, Werner CM: Increased pelvic incidence may lead to arthritis and sagittal orientation of the facet joints at the lower lumbar spine. BMC Med Imaging 13:34, 2013

17. Johnson RD, Valore A, Villaminar A, Comisso M, Balsano M: Sagittal balance and pelvic parameters: a paradigm shift in spinal surgery. J Clin Neurosci 20:191-196, 2013

18. Kanemura T, Yoshida G, Ishikawa Y: Sagittal spino-pelvic alignment in an asymptomatic Japanese population. J Spine Res 2:52-58, 2011

19. Kang KB, Kim YJ, Muzaffar N, Yang JH, Kim YB, Yeo ED: Changes of sagittal spinopelvic parameters in normal Koreans with age over 50. Asian Spine J 4:96-101, 2010

20. Labelle H, Roussouly P, Berthonnaud E, Transfeldt E, O’Brien M, Chopin D, et al: Spondylolisthesis, pelvic incidence, and spinopelvic balance: a correlation study. Spine (Phila Pa 1976) 29:20492054, 2004

21. Lee CS, Chung SS, Park SJ, Cho KH, Shin SK: The association of lumbosacral sagittal alignments and the patterns of lumbar disc degeneration. J Korean Soc Spine Surg 19(4):145-151, 2012

22. Legaye J: Influence of age and sagittal balance of the spine on the value of the pelvic incidence. Eur Spine J 23:1394-1399, 2014 
23. Legaye J: The femoro-sacral posterior angle: an anatomical sagittal pelvic parameter usable with dome-shaped sacrum. Eur Spine J 16:219-225, 2007

24. Legaye J, Duval-Beaupère G, Hecquet J, Marty C: Pelvic incidence: a fundamental pelvic parameter for three-dimensional regulation of spinal sagittal curves. Eur Spine J 7:99-103, 1998

25. Mac-Thiong JM, Berthonnaud E, Dimar JR 2nd, Betz RR, Labelle $\mathrm{H}$ : Sagittal alignment of the spine and pelvis during growth. Spine (Phila Pa 1976) 29:1642-1647, 2004

26. Mac-Thiong JM, Labelle H, Berthonnaud E, Betz RR, Roussouly P: Sagittal spinopelvic balance in normal children and adolescents. Eur Spine J 16:227-234, 2007

27. Mac-Thiong JM, Roussouly P, Berthonnaud E, Guigui P: Sagittal parameters of global spinal balance: normative values from a prospective cohort of seven hundred nine Caucasian asymptomatic adults. Spine (Phila Pa 1976) 35:E1193-1198, 2010

28. Mangione P, Gomez D, Senegas J: Study of the course of the incidence angle during growth. Eur Spine J 6:163-167, 1997

29. Marty C, Boisaubert B, Descamps H, Montigny JP, Hecquet J, Legaye J, et al: The sagittal anatomy of the sacrum among young adults, infants, and spondylolisthesis patients. Eur Spine J 11:119125,2002

30. Mendoza-Lattes S, Ries Z, Gao Y, Weinstein SL: Natural history of spinopelvic alignment differs from symptomatic deformity of the spine. Spine (Phila Pa 1976) 35:E792-798, 2010

31. Roussouly P, Gollogly S, Berthonnaud E, Dimnet J: Classification of the normal variation in the sagittal alignment of the human lumbar spine and pelvis in the standing position. Spine (Phila Pa
1976) 30:346-353, 2005

32. Schwab F, Lafage V, Boyce R, Skalli W, Farcy JP: Gravity line analysis in adult volunteers: age-related correlation with spinal parameters, pelvic parameters, and foot position. Spine (Phila Pa 1976) 31:E959-967, 2006

33. Schwab F, Lafage V, Patel A, Farcy JP: Sagittal plane considerations and the pelvis in the adult patient. Spine (Phila Pa 1976) 34:18281833, 2009

34. Schwab F, Patel A, Ungar B, Farcy JP, Lafage V: Adult spinal deformity-postoperative standing imbalance: how much can you tolerate? An overview of key parameters in assessing alignment and planning corrective surgery. Spine (Phila Pa 1976) 35:2224-2231, 2010

35. Toy JO, Tinley JC, Eubanks JD, Qureshi SA, Ahn NU: Correlation of sacropelvic geometry with disc degeneration in spondylolytic cadaver specimens. Spine (Phila Pa 1976) 37:E10-15, 2012

36. Vaz G, Roussouly P, Berthonnaud E, Dimnet J: Sagittal morphology and equilibrium of pelvis and spine. Eur Spine J 11:80-87, 2002

37. Vialle R, Levassor N, Rillardon L, Templier A, Skalli W, Guigui P: Radiographic analysis of the sagittal alignment and balance of the spine in asymptomatic subjects. J Bone Joint Surg Am 87:260267, 2005

38. Vrtovec T, Janssen MM, Likar B, Castelein RM, Viergever MA, Pernuš F: Evaluation of pelvic morphology in the sagittal plane. Spine J 13:1500-1509, 2013

39. Vrtovec T, Janssen MM, Pernuš F, Castelein RM, Viergever MA: Analysis of pelvic incidence from 3-dimensional images of a normal population. Spine (Phila Pa 1976) 37:E479-485, 2012 